\title{
Careers
}

\section{Aspirations of unemployed international medical graduates in the UK}

\begin{abstract}
The trials and tribulations of immigrant professionals such as international medical graduates (IMGs) to the UK has been a topic for discussion and debate over many years. Many challenges faced by immigrant doctors have been reviewed and reformed over a time and many rules pertaining to the registration and induction of international doctors to UK practice has been modified to facilitate safe delivery of care in the UK National Health Service (NHS). The General Medical Council (GMC), NHS employers, and the UK Home Office contribute to a three-tier filtration sieve for selecting suitable IMGs who aspire to either education and training or pursue a career in UK health and care sector.
\end{abstract}

This article pertains to the cohort of IMGs, who have been cleared by immigration regulations to reside in UK but have not been able to initiate a career or active employment as a medical profession. The process of GMC registration referred to and discussed in this article is based on GMC rules prior to Jan 2021. The perspective from which some of the attributes of the current system has been observed has shown it to be efficient but not uniform, robust but not considerate, thorough but not perfect. During the research for this article, we realised that there are many a differing opinion or conflicting views on this topic, which have all developed either from an individual or a group's own experience in the UK. There are similarities and differences in opinions and thus to broaden the scope of the discussion, we report the results of a survey exploring where and how the IMGs (currently resident in UK) are at the start of their careers in UK.

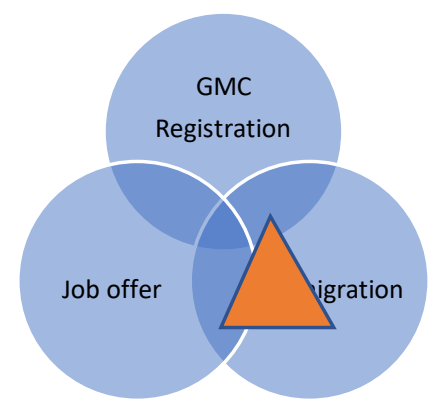

The Employed UK IMGs (Fig 1) $\triangle$

\author{
Montila Ghosh ${ }^{1}$ \& Suvalagna \\ Chatterjee $^{2}$
}

${ }^{1}$ Speciality Doctor, Obstetrics and Gynaecology, St Mary's Hospital, Manchester University Foundation Trust, Machester, UK

2 Clinical Research Fellow, Obstetrics and Gynaecology, University Hospitals Coventry \& Warwickshire, Coventry, UK

Correspondence to montilagbanerjee@gmail.com

Cite as: Ghosh, M. \& Chatterjee, S. (2021) Aspirations of unemployed international medical graduates in the UK. Sushruta J Health Policy \& Opin Vol 14 | Issue 2 | 1-9 ePub: 1 May 2021 DOI: https://doi.org/10.38192/14.2.2

Article Information

Submitted 28.4.21

Published 1.5.21

Revised 4.5.21

ISSN 2732-5164 (Online)

ISSN 2732-5156 (Print)

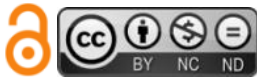


The UK healthcare system has been a favoured destination for many International Medical Graduates, especially from Commonwealth or English-speaking countries, aspiring to gain postgraduate or specialist qualifications. The UK NHS has been dependent for almost a third of its medical staff to be employed from IMGs. However, there have been rising levels of unemployment among IMGs in the UK. It is estimated that the skewed career structure of the NHS (often steeped unfavourably for the IMGs) may have stemmed from the 1930 withdrawal of General Medical Council recognition for Indian degrees. From 2001 immigration to the UK surged just when UK medical schools were increasing their output resulting in severe unemployment among IMGs. The changing visa restrictions put in place to correct this and the UK Home Office's culture of unfavourable environment policy was designed to engineer additional hurdles (financial and social) and serve as a deterrent for IMGs to come to the UK even for short periods of experience. This led to huge numbers of IMGs leaving the UK for India, Australia and USA in 1997, when access to higher specialist training became restricted to UK graduates.

However, the Medical Training Initiative visa category offered an alternative and allowed them the opportunity to gain up to two years' UK experience. The NHS has been in debt to IMGs and the countries that trained them since its inception. [1,2] The number of international medical graduates (IMGs) passing the Professional and Linguistic Assessment Board (PLAB) examination was six times greater in 2004 than in 2000, resulting in unprecedented numbers of applicants for junior posts, some attracting over 1,000 overseas graduates.

The Royal College of Physicians working group on IMGs was established in 2004 to address the problems and ascertained ways of selecting applicants when such large numbers apply for posts and has looked at ways of improving clinical attachments. [3] IMGs have faced many challenges including lack of information about the UK health system; language and communication challenges; clinical, educational and work-culture challenges; and discrimination challenges are some of the difficulties that overseas doctors might experience. [4] The common educational barriers faced by IMGs were related to lack of appreciation of the values and structure of the NHS, ethical and medicolegal issues, receiving feedback from colleagues and the different learning strategies in the UK.

The introduction of a mandatory dedicated induction program in the form of formal teaching sessions, a supervised shadowing period prior in the first job in the UK and assistance with preparation for the UK assessment systems before taking the PLAB examinations to address specific educational needs such as NHS structure and prevalent medico-legal practices, guidance and policies. Other measures such as buddying schemes with senior IMGs and educating NHS staff on different needs of IMGs should also be considered.

However, Medical Training Initiative (MTI) schemes are not accessible to a large proportion of IMGs who are ordinarily resident in the UK as dependent family members. These IMGs do not have access to any of the resources or clinical observerships and therefore face many additional and unique challenges in completing their registration and gain employment in the UK health care system. Their views and opinions are hardly aired, their existence is rarely realised and thus their problems remain unaddressed. Hence, this article will focus on the results of a survey of their career aspirations.

\section{Methods}

An online survey was conducted through social networks of doctors targeting those who were resident in the UK who are yet to start work as a doctor. There were 83 responses that were considered relevant to this article.

There were 51 respondents (62\%) who were in the UK as a dependent of another UK-employed person (Fig 2). They did not have their career plans sorted before coming to UK. The total numbers of years of stay in UK were distributed as shown in Fig 3.

There were 26 (31\%) who were eligible to get indefinite leave to remain (5 -10 years ) or citizenship (6-11 years) in the UK but in all these years of stay, they had not been able to work in UK as a medical professional. 


\section{FIG 2-UK RESIDENCY STATUS OF NON WORKING DOCTORS}
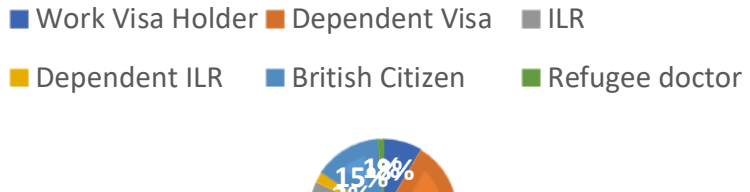

Fig 3-YEARS OF STAY IN UK AS NON WORKING DOCTORS

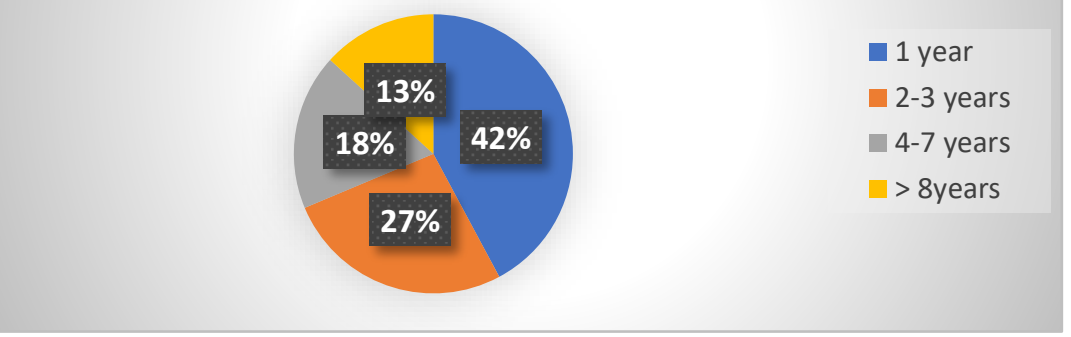

Why are they not working?

There were 43 (52\%) respondents who were either not registered with the GMC or were preparing for the Professional and Linguistic Board (PLAB) assessments, a pre-requisite for majority of nonEuropean Economic Area (EEA) doctors to register with the GMC.
In the "others" group (29\%), there were doctors trying to prove their proficiency in English as a foreign language for several years, again a prerequisite for registration with the GMC, previously which was for non-EEA doctors who had their primary medical qualifications in English, unlike non-EEA doctors. Some who had been successfully registered (6\%) were facing rejections during long listing or short listing and in interviews for employment.

\section{FIG 4- WHY ARE THESE DOCTORS} NOT WORKING IN UK

- Not registered with GMC

negistered but no License to Practice

- Preparing for PLAB

Preparing for Membership 
There is a perception that many doctors may give up their careers for the sake of supporting young children or their families. In our survey approximately 7\% quoted family reasons for not being in active employment.

Table 1-Routes for registration with the GMC UK for IMGs

\begin{tabular}{|c|c|c|}
\hline $\begin{array}{l}\text { Routes to } \\
\text { Registration }\end{array}$ & Aware & Attempted \\
\hline PLAB & 77 & 70 \\
\hline MTI & 27 & 4 \\
\hline $\begin{array}{l}\text { Sponsorship by } \\
\text { Sponsoring bodies }\end{array}$ & 17 & 3 \\
\hline $\begin{array}{l}\text { Acceptable } \\
\text { Postgraduate } \\
\text { qualifications }\end{array}$ & 29 & 13 \\
\hline $\begin{array}{l}\text { Eligibility to Enter } \\
\text { Specialist Register }\end{array}$ & 17 & 7 \\
\hline
\end{tabular}

\section{Registration}

GMC has five routes to registration, namely PLAB, Medical Training Initiative (MTI), sponsorship by the Medical Royal Colleges, recognised postgraduate qualifications and eligibility to enter the specialist register. Data presented in table 1, demonstrated that the respondents were aware of and attempted to obtain their registration via PLAB, postgraduate qualifications and MTI pathways.
Intention to leave the $U K$

The survey also showed, doctors had been waiting in average 1-3 years even after clearing PLAB. Over $61 \%$ of doctors were either unsure or sure of their intention to leave the UK if they remained unemployed, fig 5 .

\section{Fig 5-Will they leave UK?}

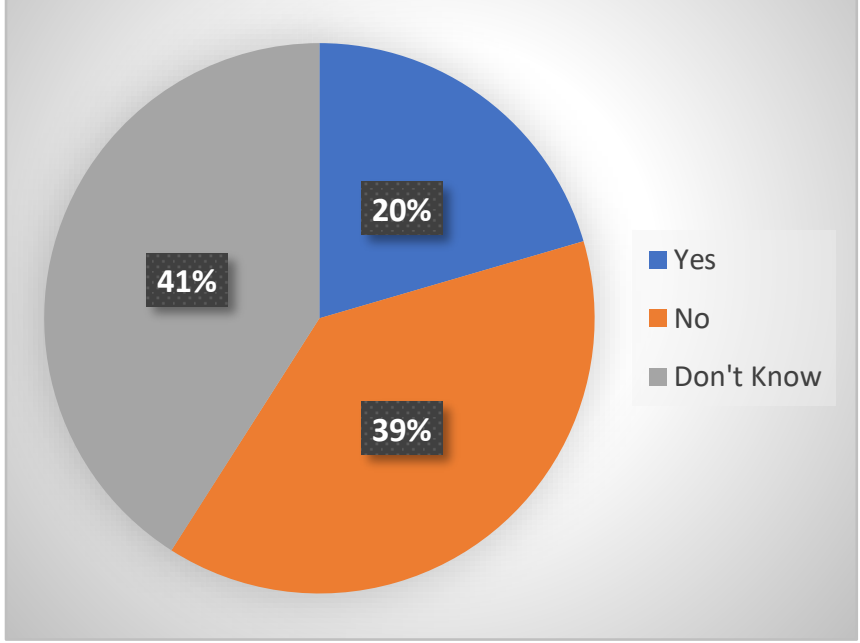




\section{Career intentions}

Table 2 illustrates the aspirations of the respondents which were intention to remain

Table 2: Career aspirations

\begin{tabular}{|l|c|}
\hline Work as a doctor & $52 / 83$ \\
\hline $\begin{array}{l}\text { Work in a non-medical } \\
\text { field }\end{array}$ & 0 \\
\hline Stay with Family & $55 / 83$ \\
\hline Post graduate training & $22 / 83$ \\
\hline $\begin{array}{l}\text { Post graduate } \\
\text { qualification }\end{array}$ & $14 / 83$ \\
\hline \begin{tabular}{l} 
Other (please specify): \\
\hline
\end{tabular} & $1 / 83$ \\
\hline
\end{tabular}

\section{Discussion}

The UK health and care system trains approximately $10 \mathrm{k}$ doctors per year and has a declared deficit of trained professionals amounting to around $10 \mathrm{k}$ doctors and $100 \mathrm{k}$ nurses. It is well known that there were more doctors IMGs registering with the GMC in 2017, then UK trained doctors. The NHS has approximately $37 \%$ of doctors who have a professional medical qualification obtained outside the UK and since Brexit, the demand for trained healthcare professionals from outside the European Union has become more acute. The societal cost for training one doctor in the UK amounts to approximately $£ 250 \mathrm{k}$ at current costs, so UK healthcare system and the country's economy gains hugely for each international healthcare professional that joins the service. The acute shortage of health care professionals was further highlighted during the COVID-19 pandemic. Under these circumstances, one would assume that the UK healthcare system would encourage and facilitate the registration and employment of trained healthcare staff to abate the persistent and worsening workforce crisis.

Our survey was designed to explore the career aspirations of international medical graduates who were resident in the UK based on their immigration status but remained unemployed. These are doctors who were already in the UK and thus would be the with their families, seek work as a doctor or pursue a postgraduate qualification. quickest to induct into service in the hour of most need. Yet the experience of most IMGs is vastly different from this and our survey has highlighted this clearly. Our survey revealed that the vast majority of respondents faced an often unsurmountable barrier of either the PLAB assessment or proficiency in English tests.

\section{Is PLAB the most efficient route to employ international doctors?}

The PLAB assessment has been the mainstay of GMC's registration route for IMGs for several years. There is moderate evidence to suggest that performance in the PLAB assessment may correlate with performance in later careers including the risk of being reported to the GMC for clinical issues (Fitness to Practice- FtP). The odds for PLAB IMGs to have obtained satisfactory outcomes at all ARCPs taken were roughly $40 \%$ lower compared to UK graduates, even after adjusting for the number of ARCPs taken, age and sex and not much different to EEA graduates who had not taken the PLAB test. The IELTS is the main (though not only) route by which IMGs are able to qualify for entry to the PLAB. The review findings suggested that raising the IELTS pass score to 8.5 or 9.0 is likely to reduce the difference in performance at ARCP between IMGs and UK graduates, but there is a perception that the threshold is set too high and may even be challenging for UK medical graduates. The 
Occupational Exam Test (OET) is considered to be more acceptable and relevant to clinical practice. As might be expected, increasing the IELTS score at which the PLAB could be taken would be unlikely to eradicate such an inter-group difference, even allowing for the number of ARCPs taken, sex, age and years of UK-based experience. Increasing the PLAB Part I pass mark by around 27 points is likely to result in IMG and UK graduate performance at ARCP being comparable (adjusting for the effects of the potential confounders listed earlier), though only around one sixth of candidates achieve such high marks currently. Likewise, raising the PLAB part 2 pass score by around 12 points will result in IMGs that perform roughly as well as UK graduates at ARCP, adjusting for the effects of potential confounding factors. However, it should be noted that currently only around one twelfth of PLAB candidates achieve that score level. This review considered a satisfactory outcome in ARCP as the benchmark, which was weak as shown by the incredible variability in ARCP outcomes and panel consistency. [5]

An independent review suggested that although the PLAB assessment methodology was considered defensible, there were several areas for improvement in the cut-off used, a need for increased transparency in the results, and assessment of the impact of demographic factors on performance. In addition, the GMC should consider a strategic approach to assessment using 'Interim' Registration followed by Workplace Based Assessment (which could include patient feedback) for a defined period as part of PLAB assessment. There could be a process of linking this with PLAB Part 1 and 2 results in a portfolio for overall assessment before grant of Full Registration. [6] In an attempt to provide consistency between IMGs and UK trained medical graduates, GMC will be introducing the medical licensing examination from 2022 , which will bring parity, as is the practice in the USA.

Regarding FtP, PLAB IMGs were more likely than UK graduates to be referred or censured in relation to FtP. The differences in rates of PLAB IMGs referred for FtP were still significant, though greatly reduced in magnitude, once the effects of sex, age and UK-based experience were controlled for. However, after adjusting for these potential confounding factors there was no difference in the odds of a PLAB IMG being actually censured in relation to FtP. [5]
The second most popular route for registration to work in the UK is via the MTI route. Doctors registering via the MTI route are usually employed at specialist registrar level, therefore likely to be expected to perform at higher and more autonomous level then PLAB registrants. The selection process via MTI is not through a common exam and the different specialities earmark their qualification and experience requirement for the post. Majority of these doctors do not require to demonstrate proficiency through an exam like PLAB. Some specialities need completed Royal College examinations, but not all. Though this route renders a tier 5 visa, restricted for 2 years, the GMC registration gained through MTI route is permanent. After the 2 year stay, with their UK working experience, they become favourable candidates for further employability now on an unrestricted visa (tier 2) when they return to the UK to continue their career. It seems that in comparison to PLAB candidates, those entering through the MTI route are anecdotally more successful in completing their training or continue working as Specialty doctors.

Unfortunately, their dependents who now come to UK on a tier 2 dependant visa, lose the opportunity of MTI route, simply because their UK residency status has changed, and they must prove their efficiency through PLAB assessments. During the COVID-19 pandemic the access to PLAB assessments has been significantly restricted hence compounding the challenge.

'Over 1000 MTI seats are available to non-resident UK doctors per year and this number is planned to be increased but this is selectively closed to doctors who have come to UK to join family.'

While there are huge workforce challenges, a large proportion of the 13200 candidates who have passed PLAB assessments between Aug 2016-Aug 2019 , have not secured employment in the UK NHS. The survey showed, doctors had been waiting in average 1-3 years even after passing PLAB for employment and it's much more challenging for the doctors waiting in the UK for jobs, while being unemployed, in comparison to the ones who are still working and earning in their respective countries. After all the cost of exams and visas for a doctor's family in UK could be a significant drain on family finances, as seen in table 3 . 
Table 3: A representative example of expense of an IMG family of 3 members are as below:

\begin{tabular}{|l|l|l|}
\hline $\begin{array}{l}\text { Immigration and Naturalisation } \\
\text { fees }\end{array}$ & Professional registration Fees & Exam fees \\
\hline $12,000-14,000$ in 5 years & $500-1000 /$ year & $500-800 /$ attempt \\
\hline
\end{tabular}

Though this survey was done using social networks of doctors, there have been many comments sent in by respondents narrating personal stories of doctors who have either finally started working in UK after a long struggle or who are still striving for it. There are examples of those who have failed the English language component several times or run out of attempts having failed by $<1 \%$ from the arbitrary cut-off threshold. Unfortunately, there is no infrastructure or established mechanism for the GMC to provide formative feedback to the ones who have been unsuccessful in the PLAB assessments. Hence, little opportunity for the candidates to improve or take appropriate actions before their next attempt. Commercially run courses are often at prohibitive cost and out of reach of many unemployed doctors.

Another observation was that membership examinations for the Medical Royal Colleges often depend on familiarity with the UK health care system and is unlikely to be an option for those who have no access to clinical observership or honorary appointments. There is significant differential attainment for IMGs taking the medical royal college postgraduate examinations based on their characteristics. [7]

GMC also advises doctors who has failed PLAB to go back to their country for further practice before retaking exam. Could this be applicable for doctors who are already resident in UK? Is the exposure to work in their home countries, more applicable than UK work experience? From our survey, it appeared that although many respondents are keen to stay in the UK in order to be with their families, a large proportion are either unsure or keen to leave. Unlike the current trend of UK graduates to leave the country after completion of their foundation years, these IMGs are keen to join and contribute to the UK health and care system. Many have opted to join the GMC Temporary Register, purely to offer their service during the unprecedented times of Covid 19.

\section{Limitations}

The data from our survey and our conclusions are focussed on a sub-cohort of doctors who have been in the UK for at least 5 years and more. This survey was mostly distributed on social networks where there is a noticeably large proportion of doctors within 1-3 years of being in the UK, however the focus of the article is towards those who have been in the UK for longer and therefore are more likely to be invested in the UK NHS and way of life.

\section{Conclusion}

In our perspective, there could be major gains from a little change in the system that could help bring back to the profession some eligible IMG doctors who are facing major hurdles and often years to prove their capability through the PLAB examinations. If the GMC were to adopt the route of interim registration and clinical placement work based assessments like current foundation doctors, it would allow this cohort of doctors to contribute to the NHS and gain experience through time-tested supervised, apprenticeship model of learning on the job in Foundation doctor roles. This would be an alternative to the PLAB OSCE assessments. 
In table 3, the authors have recommended changes for the GMC.

\begin{tabular}{|c|c|}
\hline What we have & What we can do \\
\hline $\begin{array}{l}\text { 1.We already have different routes to registration, } \\
\text { and each is quite unique in its criteria } \\
\text { 2.We have a quantitative feedback for PLAB exam } \\
\text { result but qualitative feedback for Royal college } \\
\text { exams } \\
\text { 3. IELTS /OET assessment requirement before } \\
\text { Registration with } 2 \text { years validity } \\
\text { 4. Clinical attachment post GMC registration, } \\
\text { before employment } \\
\text { 5. Workshop for new IMG joining work } \\
\text { 6. We gave early registration to our Medical } \\
\text { students to cope with Covid }\end{array}$ & $\begin{array}{l}\text { 1. A bit more flexibility and clarity so that } \\
\text { the routes like Sponsorship can be } \\
\text { applied to the relevant doctors. } \\
\text { 2. A detailed feedback that can help } \\
\text { candidates cover marginal differences in } \\
\text { PLAB. } \\
\text { 3. At least for UK residents-allow alternate } \\
\text { proof for English if already has met } \\
\text { IETLS/OET criteria once but it has } \\
\text { expired } \\
\text { 4. Clinical attachment/Work under } \\
\text { supervision/Temporary registration } \\
\text { while awaiting GMC/employment } \\
\text { 5. Workshops on opportunities of work -- } \\
\text { clinical and non-clinical/research areas } \\
\text { to facilitate skill development and } \\
\text { earning. } \\
\text { 6. Considering IMGs awaiting GMC be given } \\
\text { a Temporary registration during COVID- } \\
\text { 19 }\end{array}$ \\
\hline
\end{tabular}

\section{Bibliography}

1 Trewby P. International medical graduates: lessons from the past and hopes for the future. Clin Med (Lond) 2008;8:283-7. doi:10.7861/clinmedicine.8-3-283

2 Bhat M, Ajaz A, Zaman N. Difficulties for international medical graduates working in the NHS. BMJ 2014;348. doi:10.1136/bmj.g3120

3 Trewby PN. Assisting international medical graduates applying for their first post in the UK: what should be done? Clin Med (Lond) 2005;5:126-32. doi:10.7861/clinmedicine.5-2126

4 Jalal M, Bardhan KD, Sanders D, et al. INTERNATIONAL: Overseas doctors of the NHS: migration, transition, challenges and towards resolution. Future Healthc J 2019;6:76-81. doi:10.7861/futurehosp.6-1-76

5 Tiffin DPA, Illing J, Webster DL, et al. The Validity of the Professional and Linguistic Assessments Board (PLAB) Exam: Research Report. ;:41.

6 McLachlan PJ, Illing PJ, Rothwell C, et al. Developing an evidence base for the Professional and Linguistic Assessments Board (PLAB) Test. ;:87.

7 Dave S, Chakravorty I, Menon G, et al. Differential Attainment in Summative Assessments within Postgraduate Medical Education \& Training: Sushruta Journal of Health Policy \& Opinion 2020;13. doi:10.38192/13.3.15 